This is an electronic reprint of the original article. This reprint may differ from the original in pagination and typographic detail.

Author(s): White, William J.; Arjoranta, Jonne; Hitchens, Michael; Peterson, Jon; Torner, Evan; Walton, Jonathan

Title: $\quad$ Tabletop Role-Playing Games

Year: $\quad 2018$

Version:

Please cite the original version:

White, W. J., Arjoranta, J., Hitchens, M., Peterson, J., Torner, E., \& Walton, J. (2018). Tabletop Role-Playing Games. In S. Deterding, \& J. Zagal (Eds.), Role-Playing Game Studies : Transmedia Foundations. Routledge.

All material supplied via JYX is protected by copyright and other intellectual property rights, and duplication or sale of all or part of any of the repository collections is not permitted, except that material may be duplicated by you for your research use or educational purposes in electronic or print form. You must obtain permission for any other use. Electronic or print copies may not be offered, whether for sale or otherwise to anyone who is not an authorised user. 


\title{
4 TABLETOP ROLE-PLAYING GAMES
}

\author{
William J. White, Jonne Arjoranta, Michael Hitchens, Jon Peterson, \\ Evan Torner, and Jonathan Walton
}

\subsection{Introduction}

This chapter discusses tabletop role-playing games (TRPGs), sometimes also called "pen and paper" RPGs to distinguish them from their compatriot medium, the computer role-playing game (CRPG). Once some preliminary matters of definition and description are taken care of, the discussion in this chapter then proceeds largely along historical lines, presenting TRPGs as (1) originating in the early 1970s with the publication of Dungeons \& Dragons and its early offshoots, imitators, and derivations and (2) developing in variety through the 1980s and 1990s as designers sought to emulate different fictional settings and genres as well as explore various game-mechanical approaches before (3) experiencing a period of "mainstream" consolidation and countervailing "indie" experimentation in the first years of the $21^{\text {st }}$ century. It concludes with an attempt to discern the direction of future developments, as the arrival of crowdfunding, print-ondemand, and other Internet-enabled publishing tools change the face of the TRPG business.

The historical arc traced in this chapter draws in large measure upon two recent histories of the origins of TRPGs, Peterson's Playing at the World 
(Peterson 2012) and Appelcline's multi-volume Designers and Dragons (Appelcline 2013). Peterson describes the precursors to and influences upon the development of Dungeons \& Dragons as well as the early history of the game itself, while Appelcline details the fortunes of the myriad TRPG publishers that emerged, decade by decade, in the wake of $D \& D$ 's publication. These works provide detailed overviews of the history of role-playing game publishing, extending earlier, briefer accounts but in large measure confirming their outlines. Erik Mona, for example, alludes to the origins of $D \& D$ as an offshoot of the miniatures wargaming hobby (Mona, 2007), but Peterson's account shows how the social networks of U.S. wargamers extant in the late 1960s and early 1970s were instrumental in facilitating the creation and dissemination of role-playing games in their infancy, and Appelcline describes how the wargaming culture affected the reception of Dungeons \& Dragons as a set of rules. Similarly, Michael J. Tresca connects the original popularity of fantasy role-playing to a pop-cultural desire to appreciate the work of J.R.R. Tolkien (Tresca, 2011), but Peterson traces the origins of specific $D \& D$ rules and terms to their sources in $20^{\text {th }}$ century fantasy and science fiction, and both Appelcline and Peterson describe some of the legal ramifications and rhetorical strategies surrounding $D \& D$ 's use of Tolkien-derived material.

Our presentation of TRPGs as a coherent form relies to a large extent on their textual character. In other words, the enacted performance of TRPG play at 
the table is a kind of tertiary authorship that emerges in conjunction with the secondary authorship of the gamemaster as story-builder or scenario writer, which mediates the primary authorship of the game designer as world-builder and rules-maker (Hammer, 2007). The stability of those procedures in general terms over time and across playgroups can perhaps be attributed to the enormous influence of Dungeons \& Dragons on early TRPGs at least; $D \& D$ served as the originary text to which other designers were reacting or responding. Because of this complex textual character, we also look to accounts of play and of the reception of particular games as a method for understanding trends and themes in the evolution of TRPGs.

We focus on the North American currents of TRPG development, which took place at least initially among communities that were largely made up of white, middle-class, English-speaking males (Fine 1983). However, we recognize that this may give short shrift to developments originating in non-Anglophone communities of play. For example, a case can be made that the German FOLLOW group, whose D\&D-inspired role-playing game Empires of Magiralater renamed Midgard (Verlag für Fantasy und SF-Spiele, 1981)—was set in a world based on a long-running tabletop wargame called Armageddon, exerted some influence on the UK gaming scene via its participation in the 1970 HeiCon. However, the influence of English-speaking TRPGs on the European gaming scene was stronger and more direct, and even popular mass-market European 
TRPGs such as Germany's Das Schwarze Auge (Schmidt Spiel \& Knaur Verlag, 1984) and France's Bloodlust (Croc, 1991) and Malefices (Jeux Descartes, 1985) were not much noticed in the US, although the less whimsical 1997 English adaptation (as In Nomine) by Steve Jackson Games of the 1989 French game In Nomine Satanis/Magna Veritas (Croc, 1989) received an award for graphic design despite a mixed reception of its organization and mechanics. More recently, however, English language games by European designers, such as James Raggi's self-published 2010 game Lamentations of the Flame Princess, an "Old School Renaissance" version of $D \& D$ emphasizing its roots in pulp fiction weird tales, have challenged the unidirectional flow of TRPG innovations.

\subsection{Definitions and forms}

Tabletop role-playing games (TRPGs) or pen-and-paper RPGs have, as the names suggest, been traditionally played around tables and with pens (or pencils) and paper. As the first historical example recognized as a form of role-playing game, it is often the starting point or prototypical example thought of when people are discussing role-playing games.

\subsubsection{The Prototypical Form}

Definitions of role-playing games tend to reflect this prototypicality, but are usually not limited to TRPGs (e.g. Hitchens \& Drachen 2008). The first academic study of role-playing as an activity focused on TRPGs with a fantasy setting (Fine 1983). Fine relied on an earlier definition of fantasy roleplaying as "any game 
which allows a number of players to assume imaginary characters and operate with some degree of freedom in an imaginary environment" (Lortz 1979). Lortz was writing for a gaming magazine, not an academic outlet, and is an early example of role-playing's interest in self-analysis, continued through such examples as the Forge (Healy \& Edwards 1999). At the early stage of development at which Lortz was writing, all roleplaying was carried out around a table, with pens and paper and other accoutrements, so distinction was unnecessary. It was only with the appearance of other forms (such as computer role-playing and larps) that the ancestral form needed identification. The terms table-top roleplaying and pen-and-paper roleplaying are interchangeable, each capturing something essential to the form, but neither wholly supplanting the other. For consistency, and without denigrating the other term, we will use TRPG. Typical features of TRPGs include:

- Physical aids for play, including but not limited to rule- and sourcebooks, dice, cards, character sheets, maps and figures. These are usually not indexical, as in larps, but symbolic, working as reference materials and textual or graphic descriptions.

- Verbal description of the game events with varying, but typically low, amounts of enactment or performance of play events-TRPGs "tend to be more told than enacted" (Dormans 2006). 
- It is also typical, but not necessary, that most of the narrative- and rulesrelated power is given to one person running the game, called variously the game master (GM), dungeon master, storyteller, master of ceremonies and other imaginative titles (see also chapter 27).

As can be seen from this list, neither tables nor pens are necessary for playing TRPGs, but they are central for two reasons: tables help in organizing all the necessary equipment for play and pens (more typically pencils) are useful for note keeping and filling in the character sheets. However, it is equally possible to play in a park with tablets (or nothing at all) for note keeping.

Game master: the person describing and portraying those elements of the world outside the player characters - such as events, settings, situations and non-player characters.

\section{Call-out 4.1.1.1: Definition of GM}

\subsubsection{Books, Rules and Worlds}

Since the original Dungeons \& Dragons (1974), the essential information, including the rules, for a TRPG has usually been published as a single book or a collection of few books (see also Jara 2013). This information contains the 
necessary knowledge to play the game. In some cases the information is divided between books, for example by dividing the information according to the contents (e.g. Rolemaster was divided between books for character creation, magic, fighting and running the game). In these cases the books were often sold in boxes that contained all the necessary equipment for playing.

It is also typical that a successful game receives additional published resources in the form of additional rules, adventures, descriptions of the game world, or other additional game aids. Games that continue to be popular receive periodical updates, in the form of new editions. For example, the most successful and long-running game system, Dungeons \& Dragons is now at its fifth edition, although inconsistent naming practices mean that there have actually been more than five versions of the game.

Most rulebooks cover three topics: rules, characters and worlds. The rules dictate how the game simulates some parts of the fictional world (Dormans 2006). Often this has been focused on combat, but different games have different foci. The rules are consulted when players are unsure what would happen in some situation in the game, for example, who would win in a fight (Bergström 2012). Sometimes the rules and the game world are heavily linked (e.g., Nobilis). In other cases the rules can serve any game world of the given genre (e.g., Fate), although even here a particular world is detailed in the published material. In rare cases the rules are flexible enough to serve many genres (e.g., GURPS). 
TRPGs often revolve around a small cast of characters that are each controlled by one player (cf. Dormans 2006). These are usually called player characters (PCs, as distinct from non-player characters or NPCs) and the rulebooks will tell players how to create their characters. These characters are typically more fleshed out than other characters in the game world, and their information is usually recorded on character sheets. These pieces of paper contain both numerical and verbal information on the character played, ranging from personality traits to numerical representations of physical strength. It is also customary that the player characters advance in some way during play, gaining more experience and skills as the game continues.

In addition to being sources of rules, the rulebooks also contain descriptions of the game's fiction. Players use these descriptions to build a common understanding of the game world and then add to that world through their own play. For example, Runequest (Chaosium, 1978) is known for its elaborate fantasy-world of Glorantha, detailed in multiple publications. In comparison, the games set in the World of Darkness (e.g., Vampire) mostly mirror our own reality, but add an elaborate history filled with vampires, werewolves and mages that spans known history and beyond. A vast array of settings exist in TRPGs, from fantasy to horror, sci-fi (of all types) to western, spy to historical to military and many others, including mixtures of two or more. 
Player character: A character portrayed by a player. Usually one per player. Player characters are the central characters of the game.

Call-out 4.1.2.1: Definition of a player character

Character sheet: the paper recording of a character. Usually reserved for player characters.

Call-out 4.1.2.2: Definition of character sheet

Most TRPGs use some form of randomness as part of their rules, to make the results of actions uncertain and more exciting. This can take many forms, from playing cards to flipping coins, but the quintessential way of doing this has been throwing dice. Typically, the rules tell what dice to roll and when, and the results dictate to some extent what happens in the fiction. The results are then interpreted by the players (often the GM) to understand what happens in the fiction. This is one of the features that sets TRPGs apart from other forms of roleplaying: rather than being enacted, some actions are simulated with dice. 


\subsubsection{How table-top role-playing games are played}

Because TRPGs are usually played around a table and run by a single person (the

GM), they tend to have a limited number of players, ranging from just two

players - one running the game, the other playing - to anything close to a dozen.

The number of players is affected by the type of game being played: games that

require a lot of personal playtime with each player are less likely to be successful

with large groups, while games that follow the classic Dungeons \& Dragons

model of troupe-play can handle more players, although even there any more than single figures is very rare.

The play-time also varies. A short game can be played in a span of few minutes to few hours, while long games can run for years. There are two typical modes of play: the one-shot, where the game is played only once and there is no intention to continue, and the campaign, which varies in length, but has an expectation of continuity, sustained by regular play. Campaign are usually built around a central narrative that provides the structure for the game.

One-shot: a single-session role-playing game, with no expectation of continuation.

Campaign: a series of role-playing sessions, forming a narrative continuum. 
Call-out: 4.1.3.1: definitions of one-shot and campaign

Some game companies (e.g. White Wolf Publishing) have created continuous campaigns that are meant to be played by all players of the game in the same fictional setting, effectively combining all games played to a central storyline, or metaplot. Some campaigns are published as supplements to the main game, containing guidelines and material for the GM on how to use the material in their own game. However, it is perhaps still typical that a significant portion of the one-shots and campaigns played are created either in collaboration between all players or created mostly by the GM and complemented by the other players. They are often based on published material or rules, but many players also find the published materials unsuitable for their playstyles and create house rules or homebrew games, which either build upon other games or are based on the game groups preferred style of play (cf. Bergström 2012).

House rules: rules deviating from the ones published in the rulebook.

Homebrew: games created for personal use. Often variations of published games.

Call-out 4.1.3.2: definitions of house rules and homebrew games 
However, it is not always easy to reconcile the play preferences of even small groups of players. People play TRPGs for different reasons. One of the models that try to explain different play preferences is Ron Edwards' (2004) GNS theory, an informal, experience-based model of different playstyles. Edwards' theory divides players into categories based on whether they prefer playing RPGs as a challenge to themselves as players (gamist), as an exploration of an internally consistent fictional world (simulationist), or as an exploration of moral or aesthetic themes (narrativist). This division highlights how players vary in their play styles and preferences (see also chapter 10).

\subsubsection{Variations}

As detailed in the previous section, there are many ways of playing TRPGs.

While the historical starting point is based on wargaming with figures, many other forms of role-playing games have since been developed.

Dungeons \& Dragons is the prototypical example of a TRPG: a fantasy role-playing game, which is run by one player and where the others each play one character of an adventuring troupe, running around a fantasy world encountering monsters and killing them. Other forms of TRPGs have questioned these assumptions, from the division of narrative power and the fantasy setting to the main activity of killing monsters.

This has led to TRPGs without GMs (e.g. Fiasco), set in a multitude of settings from science fiction (e.g., Traveller) to the historical (e.g., Ars Magica), 
and focusing on activities from romance (e.g., Pendragon) to mystery (e.g., Call of Cthulhu). TRPGs have emulated many different genres of fiction, sometimes blending several (e.g., Night's Black Agents).

Even some games that could be considered mainstream have tried to differentiate themselves from the Dungeons and Dragons tradition. For example, the WoD games cast themselves as storytelling games. A number of games take this emphasis even further, putting collaborative storytelling at the center of play (e.g., Polaris). Collaborative storytelling emphasizes the shared responsibility of the players in creating a story that they will all find satisfying. Many examples of this approach can be found in so-called "indie" games, which have experimented with mechanics and play styles. For example, Dogs in the Vineyard (2004, Lumpley Games) uses dice in connection with poker style bids to focus on moral choices. It also allows players other than the GM to affect the game world outside their characters. While not the first game to do this, its elegant use of mechanics to support this style of play earned it strong critical approval. While the support of play style by mechanic did not originate in the indie scene, Pendragon (Chaosium, 1985) being an early example, indie games have explored this design space to great effect. Another interesting example is My Life with Master (HalfMeme Press, 2005), where the mechanics support the storytelling of the players as minions of an evil master torn between their fear of the master and their selfloathing on the one hand and their desires for love and acceptance on the other. 
Other indie games have explored the possibility of GM-less games. Successful examples of this include Fiasco (Bully Pulpit Games, 2009) and Polaris (TAO Games, 2005). While the former takes a humorous approach, with events outside the players' control dictated by random results from tables, the latter focuses on tragic stories in a high fantasy world. Polaris's mechanics focus on the support players give each other in the telling of the stories of their characters, even defining the purpose of the supporting NPC roles each will take in scenes focused on a particular PC.

At the other extreme from the collaborative storytelling typified by many indie games is a competitive style of roleplaying. Dungeons and Dragons has been used as the basis for arena combat style games, where the winner is the last surviving player. One game which has competitive play as a major design focus is Agon (one.seven design, 2006), set in a mythic version of ancient Greece.

Most of the games discussed above conform to the basics of the TRPGplayers sitting around a table, using the supporting materials. Even Polaris, one of the more ambitious in terms of linking mechanics and play style, makes use of the order in which players sit around the table in determining their role in particular scenes. This is very different from a larp, where large numbers of players make use of the available space. The dividing lines between forms of role-playing games is not clear-cut, and one of the types which shows this most clearly is the Australian systemless style - although other examples, such as Danish freeform 
and the Nordic jeepform, also exhibit similar characteristics. In player numbers and roles, it matches a TRPG, having a GM and approximately five players. In play style it resembles a simple parlor larp, with players acting out their character's actions and using the available space rather than being bound to a table, although the GM does far more scene setting and description than is typical in a larp. Yet in mechanics it resembles neither. It uses no quantifiable description of the characters or their abilities, nor any random resolution system. Players are given a textual description of their characters, usually focusing on their psychological state and relationships and often written in the first person. Where decision on actions is required it is left to GM decision. Play focuses, primarily, on the social interactions between players and, to a lesser extent, the GMportrayed NPCs. This social and psychological interplay forms the mechanics of the game and in turn dictates the style of narrative best suited to such gameplay.

In many of the cases just described, it can be seen that much of the experimentation with the traditional TRPG form has been around mechanics and how they can support the story, and gameplay experience, that players seek. The TRPG is highly flexible and the search for ever better interplay between mechanic and experience will go on.

\subsection{Origins and Mainstream}

The release of Gary Gygax and Dave Arneson's Dungeons \& Dragons early in 1974 marks the beginning of the era of role-playing games. But the original 
Dungeons \& Dragons booklets did not describe themselves as a role-playing game, instead invoking the cumbersome construction, "Rules for Fantastic Medieval Wargames Campaigns, Playable with Pen and Pencil and Miniature Figures." Only gradually did the world discover that Dungeons \& Dragons as it was commonly played was more than just a wargame, and that its innovations would inspire an entire industry that spans many genres and media. ${ }^{1}$

\subsubsection{Dungeons \& Dragons}

In its starting incarnation, Dungeons \& Dragons offered players the opportunity to experience adventures in a fantastic underworld and wilderness. Players would choose names for their characters and roll for a set of abilities which aided in deciding on a class, then limited to three: Fighting-men, Magic-users, or Clerics. One participant in the game acted as the referee (later "dungeon master"), and as the rules state, "before it is possible to conduct a campaign of adventures in the mazey dungeons, it is necessary for the referee to sit down with pencil and hand and draw these labyrinths on graph paper." Much of the rules are taken up with enumerating and specifying the various monsters that might be encountered, the weapons and equipment that characters might employ, and the spells that could be cast. Players explore dungeons by engaging in a dialog with the referee, proposing actions they attempt, to which the referee responds by describing the results of

\footnotetext{
${ }^{1}$ This section largely summarizes the fifth chapter of Playing at the World (2012).
} 
these attempts. When characters encounter adversaries, the game shifts into a tactical combat mode until one side prevails. Finally, players may also direct their characters through various logistical tasks, largely to deal with the plunder collected after defeating monsters.

The first adopters of Dungeons \& Dragons were largely wargamers and members of organized science-fiction fandom. Tactical Studies Rules (TSR), the publisher of Dungeons \& Dragons, could initially afford to print only one thousand copies of the game, to be sold by mail order, and almost all of its promotion targeted the wargaming community via fanzines and conventions. In the Twin Cities of Minnesota, overlap between the local wargamer and sciencefiction communities led to Dungeons \& Dragons quickly breaking out of the confines of the traditional gamer circles.

While Dungeons \& Dragons drew heavily on existing features of wargames, it combined these into a unique game with its share of signature innovations. Virtually every reviewer who encountered Dungeons \& Dragons in its first year singled out its progression system as a novel and compelling factor. A Minneapolis commentator in March 1974 wrote, "I was intrigued by the way the results of one game could be carried over to future games: a warrior could advance in rank by virtual of number of orc killed, etc.; a wizard could acquire more spells; treasure accumulated in one venture could be used to purchase weapons and armaments for the next." While wargame campaigns frequently 
maintained continuity between sessions, tying this continuity to particular characters, which act as surrogates for the players in the game world, made Dungeons \& Dragons especially engrossing. The manner in which Dungeons \& Dragons allowed characters to accumulate experience points, and to progress in quantified level when meeting certain experience point thresholds, has proven extraordinarily influential: it not only informed later games, but it has broken out of games entirely, and is now practically synonymous with the "gamification" that permeates many aspects of contemporary culture.

Within the first year of its existence, Dungeons \& Dragons had inspired fans to experiment with altering and expanding its rules. The last page of the original Dungeons \& Dragons booklets invites this community participation, posing the question "why have us do any more of your imagining for you?" and welcoming fans to "write to us and tell about your additions, ideas, and what have you." Both wargaming and science-fiction fandoms had a long tradition of open collaboration, and the fanzines of the era record many attempts to add to the taxonomies of monsters, class, spells, and treasures in Dungeons \& Dragons. For example, the idea for a Thief class originated with Los Angeles area fans who telephoned Gygax in the spring of 1974 to describe their idea; Gygax then wrote up a system description which he first informally circulated through fanzines, played at the summer Gen Con, and later made an official game system.

\subsubsection{Early Adopters and Early Adapters}


Only months after the game appeared, some fans had already decided to reapply the core principles of Dungeons \& Dragons to entirely new games, although not initially for commercial purposes. M.A.R. Barker had played Dungeons \& Dragons with university students in Minneapolis, which led him to adapt its rules to the setting of Tekumél, an imaginary world he had previously explored as an author of fiction. The resulting game, Empire of the Petal Throne, circulated in draft form in the summer of 1974; it is especially notable for detailing a concrete setting and scenario for play, where Dungeons \& Dragons left the nature of the world entirely to the discretion of the referee. Other Minneapolis area sciencefiction fans, some of whom had informally played the game without knowing that Dungeons \& Dragons had ever been published, developed their own variant, Minneapolis Dungeon, which in its early form survives in Craig VanGrasstek's Rules to the Game of Dungeon.

Outside of the Midwest, the game faced significant obstacles to adoption. The rules were notoriously disorganized and incomplete, and some early reviewers were simply unable to decipher them. The 1974 Gen Con, a convention held in TSR's home town of Lake Geneva, gave 350 gamers from around the country the opportunity to learn the game first-hand from its designers and playtesters, to participate in tournaments, and then to bring back their knowledge of the game to their local groups. This kindled wider interest in Dungeons \& 
Dragons through various small pockets around the United States, many of which began their own campaigns and fanzines.

When the original one thousand copies of Dungeons \& Dragons had sold out at the end of the first year, TSR naturally hoped to offer additional material for sale. Two supplements appeared in 1975: in the spring Greyhawk, and at the end of the year Blackmoor. The former included two new classes, the Thief and Paladin, and also introduced rules for higher-level player characters, including new spells, monsters, and magic items. The latter added the Monk and Assassin classes and introduced the first pre-packaged adventure setting, the "Temple of the Frog." Throughout the second year, TSR furthermore printed an additional three thousand copies of the base Dungeons \& Dragons set as the popularity of the game grew. Many contemporary accounts attested that the rules were widely photocopied and that adoption far outpaced sales.

Given the game's mounting complexity, even the most dedicated players disagreed about points of rule interpretation. Doubts surrounding spell memorization, experience point awards, and the effects of reaching zero hit points gave rise to "house rules" and alternative interpretations. When TSR clarified these points, they encountered some resistance from groups that no longer recognized the authority of the game's original publisher and designers: this is perhaps best optimized by the stance of Boston fan Mark Swanson, who openly 
stated in 1975 that "Dungeons \& Dragons is too important to be left to Gary Gygax.”

The Los Angeles Science Fiction Society became so absorbed with Dungeons \& Dragons that it founded a magazine dedicated entirely to the fantasy gaming experience: Alarums \& Excursions. This magazine became a place where players and budding designers exchange reports about play, system ideas, and reviews of conventions and products. While TSR Rules had by this point started an official magazine, the Strategic Review (later folded into The Dragon), Alarums \& Excursions provided a more neutral venue, where many publically criticized the "official" design decisions coming out of Lake Geneva.

For the first year of its existence, the spread of Dungeons \& Dragons remained essentially confined to North America. By mid-1975, some gamers in the United Kingdom began to adopt it. Most notably, the protagonists behind the Games Workshop, became fans of the game and distributed it locally, especially through their magazine $O w l \& W e a s e l$. Gygax began contributing material to Walter Luc Haas's fanzine Europa, which in turn became the de facto distributor for Dungeons \& Dragons on the Continent.

It would also be in 1975 that the first close imitators of Dungeons \& Dragons began to appear in the marketplace. Some came from within TSR, others came from competitors. As an example of the first, TSR acquired the rights to Barker's Empire of the Petal Throne, and produced an expensive commercial 
version with lavish maps in the spring. By June, Ken St. Andre of Arizona began selling his Tunnels \& Trolls to fans at West Coast conventions; though nominally an independent product, the first iteration of Tunnels \& Trolls was brief and highly dependent on knowledge of Dungeons \& Dragons. The August publication of the original "Warlock" system, subtitled "How to Play $D \& D$ Without Playing $D \& D$," provided a detailed set of supplemental rules popular in the Los Angeles area as a thirty-page article in a wargaming fanzine.

The principles of Dungeons \& Dragons grew so popular that wargaming projects began to take on some of its characteristics: Game Designers Workshop produced En Garde, a simulation of Renaissance-era man-to-man combat, and appended to it some character-building elements reminiscent of the personal progression of Dungeons \& Dragons. Similarly, TSR released a Wild West setting miniature wargame called Boot Hill which contained familiar elements of characterization, though it remained focused on tactical combat. It was only after reviewers began to see several genres of games in the marketplace inspired by the character-driven nature of Dungeons \& Dragons that the term "role-playing" gained currency as the core element these games shared in common. Richard Berg's reviews in Moves in the fall of 1975 widely popularized the term; only later did it begin to appear in TSR's own product literature.

Conventions continued to prove instrumental to the spread of Dungeons \& Dragons, but here too TSR faced significant competition. Its own longstanding 
Gen Con was now challenged by an East Coast wargaming convention called Origins, though TSR obligingly supported both, even if favoring the former. The famous 120-person tournament at the first Origins convention in 1975 featured the original version of the Tomb of Horrors, which would later be published as a stand-alone adventure. Convention tournaments no doubt seeded the market for adventures sold as products, such as the Palace of the Vampire Queen (1975), which TSR distributed. The market for pre-packaged dungeon adventures even supported a bi-monthly fanzines called the Dungeoneer which shipped an adventure with every issue, beginning in 1976.

By then, the success of the early TSR Dungeons \& Dragons supplements Greyhawk and Blackmoor inspired third-party producers to create similar supplements of their own. The Manual of Aurania came from Los Angeles area fans, who contributed a mix of new classes, monsters, and spells; they did not seek any license from TSR, any more than TSR had asked for a license to their idea of a Thief class. Others however sought a business relationship with TSR as producers of official third-party supplements for Dungeons \& Dragons. In the summer of 1976, the Judges Guild secured a partnership with TSR for campaign aids including its City State of the Invincible Emperor, which brought an unprecedented level of detail to an urban medieval fantasy setting.

Some external designs went beyond just adding more Dungeons \& Dragons, instead attempting to simplify, or at clarify, its increasingly 
unmanageable rules. With the addition of the official Eldritch Wizardry supplement in 1976, and in it both the Druid class and the psionics system, the system had grown more cumbersome than ever. House rules like the "Perrin Conventions," which were distributed at the first DunDraCon in San Francisco in 1976, tried to improve the game's performance by replacing the original combat system with a more finely specified variant. Such efforts laid the groundwork for more considered competitors to Dungeons \& Dragons appearing over the next two years.

As competition mounted, TSR began using legal tactics to obstruct rival efforts. The use of the name "Dungeons \& Dragons" in unlicensed products was enough to provoke a cease-and-desist letter from TSR's attorneys. This further eroded the goodwill of the community, especially when it targeted Arneson, following his acrimonious departure from the company. Ultimately, TSR found itself locked in a struggle with its own customers for control of the canonical game. In response, many competing companies removed references to Dungeons \& Dragons from their advertising and products, substituting instead the term "role-playing game," which soon became a generic term for "a game like Dungeons \& Dragons."

By 1976, new titles pushed beyond the dungeon adventure format. Ken St. Andre, the designer of Tunnels \& Trolls, turned the original setting topsy-turvy, letting players take on the role of dungeon occupants repelling parties of 
adventurers in his Monsters! Monsters! His hybrid wargame Starfaring transported the principles of Dungeons \& Dragons, with psionics standing in for magic, to a science-fiction game. TSR itself entered the realm of science fiction with its Metamorphosis Alpha at the end of the year, a game set on an interstellar colony ship featuring mutations and forgotten technology. Metamorphosis Alpha would be the first published title to identify itself as a "role-playing game" on its cover. Finally, TSR received a proposal in 1976 for an espionage role-playing game called Top Secret, which would remain in development for nearly four years.

\subsubsection{The Second Generation}

When the original rules of Dungeons \& Dragons turned three years old, they had been augmented and amended by a raft of supplemental material which TSR had made little effort to integrate into a coherent system. This became a source of increasing consternation to players, who repeatedly called for TSR to address the problem or alternatively to grant fans permission to reorganize and edit the game themselves.

Moreover, the market began to demonstrate the advantages of consolidating and unifying role-playing game systems. Chivalry \& Sorcery serves as perhaps the best example of this drive to make the system precise and explicit: its dense rulebook abounded with charts covering a wide variety of circumstances 
neglected by Dungeons \& Dragons. With this system however came an increasing burden of complexity that ultimately rendered the game less playable.

The Arduin Grimoire came out of the same Bay Area group that produced the Perrin Conventions, premiering at the second incarnation of DunDraCon. Compared to previous unofficial supplements, its one hundred pages contained both more new material and proposed more fundamental changes to the base system. Moreover, the Arduin Grimoire did not stop at being a single stand-alone booklet; before the end of the year the author was busily cobbling together a second volume, which would be followed shortly thereafter by a third. Ultimately, the industry's efforts to capture a deeper level of simulation of fantastic adventures led to a complete revision of the original Dungeons \& Dragons product. In 1977, TSR split Dungeons \& Dragons into two parallel tracks: a "Basic" version of the game, edited by Eric Holmes; and an "Advanced" version developed under Gygax's direct supervision. The Basic version appeared in a boxed set in 1977 as a simplified introduction to the game that only guided characters through the first three levels of play; the packaging of the Basic Set positioned it for sale in traditional retail venues like booksellers and department stores. The advanced version would come out in installments over the next three years, dwarfing the word counts of Chivalry \& Sorcery and prior efforts with its increasingly rich system. 
The first task of the Advanced Dungeons \& Dragons project was organizing the game's monsters. Scattered across the original rulebooks, the supplements, and various issues of the Strategic Review and The Dragon, creatures proved difficult to locate. While independent efforts had already produced slender volumes dedicated to monsters, such as Little Soldiers's Book of Monsters (1976), TSR's Monster Manual (1977) promised to organize some 350 of its creations into a large-format hardcover book.

In this effort, as in many others, TSR faced increasing competition and criticism. Their project encompassed only the monsters endorsed by TSR's official publications - but many could be found in the pages of fanzines like Alarums \& Excursions and the Dungeoneer, in unofficial supplements like the Manual of Aurania and the Arduin Grimoire, or unpublished in campaign notes or newsletters. Steve Perrin spearheaded an effort to collect these into a volume called All the Worlds' Monsters, complete with credits for individual contributions to the project. This booklet, published by the Chaosium, reached the market before the Monster Manual, though its impact has been far less lasting. The publication of the Monster Manual was in part delayed by a legal challenge from the rights holders of J.R.R. Tolkien's works, who claimed TSR's use of terms like hobbits, ents, and balrogs infringed on their intellectual property. This required TSR to amend many of rulebooks, including the core Dungeons \& Dragons system and its supplements, including the new Holmes Basic rules. 
The second installment of the advanced system was the Players Handbook, primarily a guide to character classes, equipment, and spells. It too collected and edited material previously spread across rulebooks and magazines into a single, organized hardcover volume. It premiered at Gen Con in 1978, the same summer that TSR began marketing pre-packaged adventure "modules" along with its tournament dungeons. Modules opened a new revenue stream for TSR and its partners.

The publication of the Dungeons Masters Guide coincided with Gen Con in 1979, and completed the core trilogy of Advanced Dungeons \& Dragons. Roughly simultaneously with its publication, the disappearance of a young college student named James Dallas Egbert III set off a wave of media coverage of the game Dungeons \& Dragons. Authorities speculated that Egbert had disappeared in the steam tunnels beneath his school while playing a live-action version of the game. This speculation turned out to be baseless, but the publicity it gave to role-playing games sparked a huge increase in sales, and marks the beginning of the Dungeons \& Dragons fad. From revenues short of \$1M in 1978, TSR went to revenues over $\$ 20 \mathrm{M}$ in 1982 . Over those years, role-playing games truly became their own industry.

\subsection{The Next Wave: Differentiation and Counter-Movements}

William J. White and Evan Torner

\subsubsection{D\&D and FRPG Variants as Alternative Design Philosophies}


By 1979, Jon Freeman's well-informed Winner's Guide to Board Games could list four games as "alternatives to $D \& D$ " for those seeking adventure in quasimedieval fantasy settings: Flying Buffalo's Tunnels \& Trolls by Ken St. Andre (1975), Metagaming's Melee (1977) in combination with its companion game Wizard (1978) by Steve Jackson (who would use the design ideas pioneered in these "The Fantasy Trip" games to construct his "generic universal role-playing system" GURPS), Chaosium's Runequest (1978) by Steve Perrin, and Fantasy Games Unlimited's Chivalry \& Sorcery (1975) by Ed Simbalist and Will Backhaus (Freeman 1979).

These alternatives illustrate the range of different design philosophies that shaped game designers" efforts to "improve" $D \& D$ in the period immediately following its publication. Both $T \& T$ and Melee/Wizard were efforts to craft less complicated rules systems, emphasizing simplicity, playability, and accessibility; Flying Buffalo went so far as to offer adventure scenarios for $T \& T$ capable of being played solitaire, in the eventuality that a player was unable to find others with whom to game. Runequest, like M.A.R. Barker's earlier $D \& D$ variant Empire of the Petal Throne (TSR, 1975), focused on adventuring in a game-world that was clearly distinct from the sort-of-Europe with magic and monsters of other games; Runequest's setting, the world of Glorantha, had also been the setting for Chaosium's earlier tabletop fantasy wargames. Runequest was also notable for eschewing $D \& D$ 's system of “character classes” (e.g., fighter, magic-user, cleric, 
thief) and experience levels in favor of a more granular skill system that allowed characters to be well-rounded generalists or highly focused specialists based on how a player distributed available skill points, an innovation apparently borrowed from FGU's Watership Down-inspired game of rabbit role-playing called Bunnies and Burrows (1976) by Dennis Sustare. $C \& S$ went in the other direction from $T \& T$, a product of its designers' dissatisfaction with the lack of medieval verisimilitude in $D \& D$ (White 2013).

As the existence of Bunnies \& Burrows alluded to above implies, by the end of the 1970s, TRPG designers had already begun to move beyond the "dungeon crawl" that was the original mode of fantasy gaming by seeking to emulate other fictional genres and settings. TSR, Inc., the publisher of $D \& D$, had brought out games set in the Wild West (Boot Hill, 1975), a rudderless generation ship (Metamorphosis Alpha, 1976), and a post-apocalyptic wasteland (Gamma World, 1978). In addition to $B \& B$ in 1976, FGU had published a cops and robbers game set in the 1920s (Gangster, 1979) as well as a superhero RPG, Jeff Dee's Villains and Vigilantes, the same year; it would soon move on to feudal Japanese samurai (Bushido, 1980), post-apocalyptic marauders (Aftermath, 1981), pulp-era adventurers (Daredevil, 1982), and 17 th century French swashbucklers (Flashing Blades, 1984), among others. A number of "open world" or generic science fiction games had been published or would shortly see print by the end of the 1970s; the most well-known of these is GDW's Traveller by Marc Miller (1977), 
which eventually generated its own elaborate canonical future history describing the rise and fall of the interstellar Third Imperium and was frequently licensed to other publishers for translation into other game systems.

Dungeon-Crawling: A mode of RPG play involving the exploration of a site, such as a catacomb, tunnel complex, or ruined fortress, stipulated to exist within a larger game-world. The site's specific features and denizens are initially unknown to the player-characters, who venture inside with the goal of defeating its guardians and obtaining any treasure contained within.

Call-out 4.3.1.1: Definition of "dungeon-crawling."

In general, then quest for alternatives to $D \& D$ was oriented toward seeking out alternative mechanics, meaning different ways of representing the imaginary action or imagined abilities of fictional characters, or alternative settings, whether in the form of more richly imagined non-European game-worlds or as greater fidelity to the ostensibly medieval backdrop of $D \& D$ itself. Some games combined both elements.

For example, Jonathan Tweet's Everway (Wizards of the Coast, 1995) was centered on a fantasy city that served as a portal to many different alternate planes or "spheres," with characters who could walk between these spheres to have adventures. Character generation began with players selecting an image from a 
"vision card" and answering questions about it; the vision cards were specifically selected so as to include a wide variety of non-Western images. Even more striking than this effort to open up the setting of the game was its reliance on a tarot-like "fortune deck" from which cards could be drawn and then interpreted by the game master $(\mathrm{GM})$ in order to establish what had occurred.

A fine example of the commitment to medieval verisimilitude is Greg Stafford's Pendragon (Chaosium, 1985), in which the player-characters were Arthurian knights of the Round Table, engaging in quests and serving their lords in raid and battle while simultaneously maintaining their fiefs and siring children who would eventually grow up to follow in their fathers' footsteps (and be playercharacter knights as well), all against the backdrop of Mallory's Morte d'Arthur. But Pendragon also included the game-mechanical innovation of introducing "social attributes" that defined aspects of the character's personality in a way that could influence behavior: if a character with high Pride wanted to forgive an insult he received from a non-player character (NPC) guest of his lord, for example, the GM could call for a die roll that might result in the character refusing to bite his tongue, regardless of the player's wishes.

These two games may also illustrate an historical design trend in which during the 1980s, designers (perhaps hewing to the role-playing's roots in wargames) emphasized more complex or at least more detailed game mechanisms as solutions to their design problems, whereas in the 1990s designers began to 
explicitly emphasize mechanisms that would encourage, facilitate, or enable "role-playing" (which came to be invidiously perceived by many to be vastly superior to mechanistic "[die] roll-playing"). We do not intend a normative distinction, here, however. Both Everway and Pendragon are much admired within gaming circles, albeit for different qualities, but the former seems to be not much played anymore (except perhaps as the basis for one-off larps), while the latter still shows up each year on the schedule at GenCon, the annual gaming convention initiated by Gary Gygax in the late 1960s, if only in one or two slots.

Random character generation. Any procedure in which character aspects are established by methods of chance such as rolling dice or drawing cards, using the results either as a quantitative measure of some attribute or as an index for a table look-up.

Point-buy system. A character creation method in which character aspects are established by spending points from a budget to purchase useful traits or advantages possessed by the character; selecting negative traits or disadvantages may provide additional points to the player.

Life-path system. A character creation method involving making successive choices for a character at particular points in his or her career, such that prior 
choices influence the range of later options. Each choice may produce randomly determined consequences or accrue certain character resources or both.

Attribute auction. A very seldom used point-buy variant in which players bid points from their budget for particular character attributes; the bids are compared and then used to rank the characters along that attribute.

Call-out 4.3.1.2. Definitions of some character generation methods

\subsubsection{A Universal Revolution: Champions and GURPS}

Two games illustrate the 1980s design trend towards "universal" systems ostensibly capable of emulating multiple genres. Champions (Hero Games, 1981) by George McDonald and Steve Peterson began as a game for playing comic book super-heroes. Debuting at the 1981 Origins gaming convention being held that year on the West Coast, it made an immediate impact for its elegant, albeit somewhat arithmetically complex, system for designing super-powers. The fact that the "special effects" (i.e., in-game depiction) of those powers were distinct from their basic game-mechanical descriptions (e.g., Superman's heat vision and Green Lantern's willpower-created giant glowing green hammer could both be treated as variations of the generic power "Energy Blast"). This, with the addition

of a system for representing innate skills or talents allowed the same game system 
to plausibly represent pulp fiction and "lost world" adventures, as with Justice, Inc. (Hero Games, 1984). With this example to guide its designers, there began a transformation of Champions, a game designed to emulate super-heroes, into the Hero System (Hero Games, 1989), a role-playing toolkit intended to enable GMs to develop their own bespoke campaign settings (Allston, Long, and Watts, 2006). Meanwhile, the GURPS Basic Set (Steve Jackson Games, 1986) took Steve Jackson's initial designs for The Fantasy Trip (Metagaming, 1980) and transformed them into a "generic universal role-playing system" intended to be "detailed and realistic, logical and well-organized, and adaptable to any setting and any level of play" (Appelcline, 743). Following the publication of a tactical combat system for individual-level fights in 1985 , the basic rules provided a "point-buy" system for character creation like that of Champions, allowing the player to purchase attributes, talents, skills, and other abilities at a certain cost, perhaps offset by accepting certain disadvantages. GURPS was supported by a steady stream of supplements for specific genres, settings, and licensed properties such as the Horseclans, Conan, and Wild Cards series in the late 1980s, and Traveller, Discworld, and Hellboy in the late 1990s and early 2000s. The GURPS "world books" that describe specific historical settings and time periods have a well-deserved reputation for being high-quality reference works worth consulting even if one doesn't intend to run a GURPS-based campaign (Hite, 2014). 
Today, GURPS and the Hero System are perceived similarly by tabletop role-players, being regarded as complex in preparation albeit relatively straightforward in play. "The core of GURPS 4e [4 $4^{\text {th }}$ edition, published in 2004] is not complex," asserts an on-line commenter on the RPG.net forums. "It's a basic roll under your skill on a $3 \mathrm{~d} 6$ and that core is consistent. ... However, the other core of GURPS is the Modifications and Limitations that are the working parts in Advantages.... This was an awesome development and what makes 4e so powerful and far-ranging. But it is complex. It really takes a long time to figure out all the little details in a [game mechanical] structure" (walkerp, 2008).

\subsubsection{Peeling the Onion: Call of Cthulhu}

Sandy Petersen's Call of Cthulhu (Chaosium, 1981) adapts the intertextualized fictional universe of H.P. Lovecraft, his correspondents, and later imitators (summarized by Price 2009) to the conventions of role-playing games, pitting mortal "investigators" against malign horrors from beyond space and time. In place of the dungeon crawl, Call of Cthulhu characters become embroiled in investigations that leverage the structural similarities between detective fiction and horror stories, both of which feature stages of onset, discovery, confirmation, and confrontation (Hite 2007).

The rules text emphasizes the investigative nature of the game, suggesting that a campaign be structured like the skin of an onion, with each new surface layer peeling away to reveal a new and deeper puzzle. The disturbing revelations 
uncovered by their inquiries — or shocking face-to-face encounters with the horrors of the Cthulhu Mythos_-would prompt "Sanity checks," die rolls that could prevent the permanent loss of some amount of Sanity points, with complete madness occurring at zero Sanity (though lesser psychological maladies might emerge even earlier). This device, which "has a rather unsettling way of replicating real-life emotional problems and the way they feed upon themselves" (Herber 2007, 42), may account for the some of the game's appeal, as watching one's Sanity points dwindle in play could create an immersive feeling of suspense or anxiety on the part of the player.

Lovecraftian horror would prove quite robust, generating a number of alternate settings by Chaosium and others, including one called Delta Green (Pagan Publishing, 1997) that combined the Cthulhu Mythos with conspiracy theories and the UFO craze. The textual emphasis on investigation was not always strictly adhered to in play, as some investigators found it quite effective to load up with shotguns and dynamite in order to quash the machinations of the Mythos, and some "Keepers" (as Call of Cthulhu GMs were known) found it necessary to ignore failed skill rolls in order to avoid stymying the investigation, which meant

that, strictly speaking, the search for clues (the investigatory part of the adventure) was less important than the confrontation with the Mythos monsters at its end.

\subsubsection{Drawing Trumps: Amber Diceless}


With a new generation of role-players that had not cut their teeth on military miniatures or hex-and-chit wargames entering the hobby, Erik Wujcik's Amber Diceless Roleplaying (Phage Press, 1991) helped initiate the "storytelling game" movement of the 1990s, which sought to emphasize immersive "role-playing" rather than tactical combat simulation as the centerpiece of play. Amber was based on the novels by Roger Zelazny, beginning with Nine Princes in Amber (Doubleday, 1970), that detailed the intrigues, rivalries, and vendettas among the immortal scions of the house of Amber, an interdimensional city at the heart of reality. The game itself is illustrative of two trends that characterized the distinction between the verisimilitude-focused games of the 1980s with immersion-intensive games of the 1990s.

One of these trends was to encourage players to actively engage in the process of "doll housing" (Boss 2012), or the pre-game creation of fictional backstory for a given character. Amber rewards players with more character points in exchange for describing a character's mount, drawing a Trump card for her/him, or detailing the character's intricate relations with the house of Amber, for example. Michael Pondsmith's proto-steampunk Castle Falkenstein (R. Talsorian, 1994) offered similar blandishments.

Such emotional commitments were weighed, however, against the other design trend: the discovery of player unpredictability and social-based player vs. player (PvP) action as territory for tabletop RPGs to explore. For example, one of 
the original PvP games, Greg Costikyan's Paranoia (West End Games, 1984), uses PvP to comic effect: players play as clones in a dystopian society, and no one really cares whether a character lives or dies. Paranoia has the comforting alibi of dice too, meaning that randomness mediates this death lottery-characters die thanks to the dice, not one's fellow players. This ameliorates but does not wholly remove uncertainty as a source of tension frames player unpredictability in terms of the classic board game Diplomacy, in which players have very few game options that do not rely on direct, non-arbitrary betrayal of another player (Costikyan 2013).

In Amber, however, the attribute auction at the beginning and the deep emotional investment in one's fictional persona mean that players must already place their investments and emotional commitments on the line; a wager of a sort. Since the role-playing game is diceless, the system simply offers no alibi for when a PC is overwhelmed by another PC or an NPC: the PC and/or GM involved would be directly responsible. Ironically, the game replicates the dysfunctional family structure of the Amber novels (competitive siblings vying for the attention of a remote and arbitrary patriarch) by coding that structure into the rules, since it is exactly by gaining the attention and favor of the GM (whose interpretations of the meaning of different character attributes and actions determine the success or failure of a player's plans) that PC Amberites prosper in the game. 
Social maneuvering in courtly situations suddenly became more interesting than exploring dungeons and all of one's fellow players became one's frenemies. Player unpredictability remains the primary source of tension in Amber, even though the game otherwise promises "story" (Torner 2014).

In play, the game crystallized as standard practice the act of PCs passing notes to the GM, hitherto utilized in $D \& D$-like games mainly by PC thieves wishing to engage in a little intra-party larceny. The player would take a slip of paper and write a character action that she wouldn't want the others to see, or a question she would prefer to ask in private, and pass it to the GM, who would write a brief response on the same hidden slip and pass it back. Functionally, this democratized the GM's screen in note form: everyone had secrets, everyone had an interesting backstory, and all of this information was to be hoarded, lest one give leverage to one's enemies. Deep investment in backstory, explicit social PvP elements, and the corresponding secret-note-passing behavior all would become hallmarks of popular 1990s TRPGs. We will briefly examine two of these next.

\subsubsection{Telling Stories in the Shadows: The World of Darkness}

White Wolf Publishing's "World of Darkness" series of horror games set in the modern world, loosely inspired by Anne Rice's vampire novels, began with the publication of Mark Rein-Hagen's Vampire: The Masquerade (White Wolf, 1991), which became one of the most successful TRPGs, "second only to the lingua franca of the hobby, Dungeons \& Dragons" (Hindmarch, 2007). The 
World of Darkness games used White Wolf's "Storyteller System," which was billed as explicitly designed to facilitate the creation of good stories. A lot of the onus for this was placed on the Storyteller (i.e., GM), although later editions would attempt to redefine the balance of power between player and Storyteller more evenly. At its best, the Storyteller procedures facilitated highly immersive character-focused drama as the PCs confronted the choices laid out for them by the development of the Storyteller's narrative; at its worst, it led to disengaged play as they either resisted or succumbed to the Storyteller's efforts to "railroad" them along a predetermined course.

Railroading: Used pejoratively to refer to a style of TRPG game-mastering in which the GM prepares and runs an adventure whose course proceeds along predetermined lines without the possibility of being affected by players' in-game actions, in a way that is objectionable to the players.

Call-out 4.3.5.1. Definition of railroading.

\subsubsection{Monstrous and Crazy: Shadowrun}

One last game deserves a brief mention in the context of the differentiation of TRPGs during the 1990s is Shadowrun (FASA, 1989), which took the Tolkienderived fantasy bestiary of elves, dwarves, orcs, and dragons and ported it into a $21^{\text {st }}$ century cyberpunk universe, so that orcish cyborgs could face off against 
jacked-in elven hackers in a high-tech corporate-dominated dystopia where, nonetheless, magic worked and a dragon might be the chairman of the board. Other cyberpunk games existed but were less popular. Shadowrun adventures tended to take the form of at least mildly criminal freelance jobs offered by shadowy "Mr. Johnsons"; ideally, the PCs' involvement in these jobs would bring them into contact with the metaplot, the game's large-scale backstory in which the schemes and maneuvers of different high-level actors in the Shadowrun universe drove in-game events, in such a way as to give the players a sense of immersion in a large and complex world as well as an aesthetic appreciation of the story they were witnessing. A common complaint about metaplot-heavy games, however, was that they threatened to make the PCs marginal rather than central figures in the resulting story. Nonetheless, Shadowrun has served as the background for several modestly successful CRPGs.

\subsection{The Current State: Analog RPGs in a Digital World}

As the turn of the millennium approached, TRPG enthusiasts frequently expressed anxiety about the future of the medium and the industry. Not only had the popularity of tabletop games been irreversibly eclipsed by digital games — which survived the 1983 crash of Atari to become a multi-billion dollar-industry—but the massive success of Magic: The Gathering (1993) and the Pokémon Trading Card Game (1998 U.S. release) had made TRPGs a second-tier medium even within fantasy analog games. 
However, far from destroying TRPGs, collectable card games and digital technologies played key roles in launching and sustaining the ongoing renaissance that has taken place in TRPG design and play since 2000. One major impetus for this renaissance was Wizards of the Coast—-the publisher of Magic: The Gathering and the U.S. publisher of the Pokémon TCG—purchasing the rights to $D \& D$ and releasing a wildly successful "third" edition of the game in 2000. Wizards also released substantial portions of this new edition under an opencontent license, a decision directly inspired by open-source projects in software development.

Over the next 15 years, TRPG fans, creators, and publishers embraced this and many other practices inspired or enabled by digital technologies. New means of communication increased the interconnectedness of various TRPG communities. Digital printing, digital distribution, and online funding methods allowed new and existing publishers to more easily reach their audiences and manage financial risk. Together, these practices have forever changed the ways in which TRPGs are conceived, produced, distributed, and played, unleashing a transformation of the medium that is still ongoing.

\subsubsection{The Internet Arrives}

TRPG enthusiasts have always included a sizable number of people with strong ties to the computer and software development industries. Jon Peterson has 
described portions of the complex history between TRPGs and major figures from early networked computing and hacking communities, which is just the tip of the iceberg. ${ }^{2}$ TRPGs were discussed and played over some of the earliest networks, due to the common alignment of computing, TRPGs, and tech-savvy nerds.

By the early 1990s, the Internet began to spread to the general U.S. population. For the relatively small and dispersed hobby of roleplaying, connectivity was revolutionary. Websites conveyed information about what games were available and how fans could acquire them, reducing reliance on hearsay, hobby store employees, and ads in comic books. Newsgroups, bulletin boards, forums, mailing lists, blogs, and chat clients provided ways for distant or even local enthusiasts to find each other, organize meetings, and share their thoughts, experiences, advice, and play techniques. Publishers, creators, and fans could communicate directly.

Several specific digitally supported or digitally inspired practices fundamentally altered the ways in which TRPGs were published. These practices included online sales, media piracy, digital distribution, open content, PDF ebooks, digital printing, beta testing, print-on-demand, crowdsourcing, and crowdfunding - several of which became popular among TRPG enthusiasts prior to their more widespread adoption by the general public. While these practices

\footnotetext{
${ }^{2}$ Cite Jon's BoingBoing article, or something else if he prefers.
} 
may have seemed novel, they can be more accurately understood as the latest in a series of attempts to address longstanding issues in TRPG publishing. That said, practices such as online sales and digital distribution created additional challenges for "brick and mortar" game retailers, similar to related pressures facing independent music, movie, book, comic, and video game stores.

\subsubsection{The D20 Boom: D\&D3, Open Gaming, and Digital Distribution}

Wizards of the Coast—founded by Peter Adkinson— began as a TRPG publisher, releasing a multi-system supplement called The Primal Order (1992) and hiring designer Jonathan Tweet to create a third edition of Talislanta, which they published that same year. Tweet had previously co-designed Ars Magicka (1987) with fellow St. Olaf College student Mark Rein-Hagen - who would later go on to co-found White Wolf - and had been working on what would become the minimalist and innovative game Over The Edge (1992), partially through discussions in the venerable TRPG zine Alarums and Excursions. But the unprecedented success of Richard Garfield's collectible card game Magic: The Gathering both funded and complicated Wizards' later work on TRPGs. They purchased the rights to Ars Magica and published Everway (1995) — another minimalist and innovative game by Tweet - the commercial failure of Everway and the relative unprofitability of TPRG publishing led to the cancellation of all of Wizard's TRPG lines. 
Wizards' return to TRPGs was delayed until the acquisition of TSR in 1997. At first, Wizards mostly cleaned house at TSR: paying debts, publishing projects that were nearly finished, securing all rights to $D \& D$ from Gygax and Arneson, and making sure that Gen Con continued to happen. But in 1999, they announced a third edition of $D \& D$. The core designers of $\mathrm{D} \& \mathrm{D} 3$ included Tweet as well as Monte Cook and Skip Williams, old hands at TSR. The game shared much in common with AD\&D2 but was significantly streamlined and unified, including the notable change that all basic resolution was handled by rolling a single twenty-sided die (d20), leading to the rules framework being dubbed the "d20 system." Following the model set by AD\&D, the game was divided into three massive hardcover books, the Player's Handbook, Dungeon Master's Guide, and Monster Manual, each released months apart in 2000. These were accompanied by the Star Wars Roleplaying Game (2000), which used the d20 system. By any measure, third edition was a massive success, spawning hundreds of official products and thousands of open-content products, revitalizing both $D \& D$ and the TRPG industry as a whole. ${ }^{3}$

One of the biggest successes and challenges of the $\mathrm{d} 20$ era involved Wizards' relationship with "third-party" publishers—a term borrowed from

\footnotetext{
${ }^{3}$ Verify publication figures. See if OneBookshelf can verify "tens of thousands" of d20 products.
} 
software and digital game development. The Open Gaming License (OGL) largely the brainchild of Ryan Dancey, brand manager of the TSR properties at Wizards - allowed any publisher, of any size, to publish products derived from D\&D's core mechanics. One of D\&D's biggest strengths, it was argued, was the broad community of fans that created content and rules variants for the game. Additionally, Peter Adkinson reportedly wanted to prevent the possibility that D\&D might be "imprisoned" by a single company and driven into the ground by financial or managerial mismanagement, as it nearly was before the sale of TSR. ${ }^{4}$ In retrospect, it's astonishing that Wizards was able to go forward with the OGL despite the company having recently been acquired in 1999 by the entertainment giant Hasbro. ${ }^{5}$ While a few TRPGs had experimented with open content before, particularly the "Fudge Legal Notice" in Steffan O'Sullivan's minimalist DIY classic Fudge (1995 version), this was on a completely different level.

While an overwhelming success, the OGL did not always function as intended. Rather than drawing on the open content that their peer $\mathrm{d} 20$ publishers were creating - the OGL requires some portions of derivative products to also be open — publishers often attempted to create their own valuable IP content based solely on official D\&D products. This meant OGL products were often

\footnotetext{
${ }^{4}$ Appelcline, Designers \& Dragons, Vol. 3: The Nineties, 156.

${ }^{5}$ Note, however, that Hasbro was primarily interested in Wizards because of Magic and Pokémon, not because of their TRPG properties.
} 
idiosyncratic, rather than being a cohesive body of texts in conversation with each other. Many companies also began using the OGL to make stand-alone game products that functioned as direct or indirect competitors to the three core books of $D \& D$. This even included D\&D3 designer Monte Cook, who left Wizards and eventually published a variant take on third edition, Arcana Unearthed (2003). Mike Mearls, who would be hired by Wizards to work on later versions of D\&D, auditioned for that role partially through his own D\&D3 variant, Iron Heroes (2005). Indeed, the first real challenge to Wizards' new dominance of TRPGs would eventually come in the form of an OGL-licensed stand-alone derivative to D\&D3, Paizo Publishing's Pathfinder (2009).

Wizards' own publishing policies were partially behind the third-party shift toward stand-alone products. In 2003, Wizards surprised many publishers by releasing a slightly updated version of third edition known as Dungeons \& Dragons $v 3.5$ (borrowing decimal edition numbering from the software industry). While the changes were not too substantial, they included numerous tweaks to basic features of the game, enough to prevent easy conversion and arguably rendering many third-party products "out of date." Consequently, publishers felt incentivized to create distinct sub-brands of $D \& D$ that they controlled, rendering their design and publication choices semi-independent of whatever Wizards did. This also occurred during a period of perceived market saturation and audience 
burnout in d20 publishing, which lasted throughout the mid-2000s and contributed to d20 publishers' anxieties.

The third prong of the millennial transformation of TRPG publishingdigital distribution — initially had two main forks: digital sales of printed TRPG products and digital distribution of digital products. In terms of print products, individual publishers and brick-and-mortar game stores started selling games through their websites as soon after it became possible to accept credit cards online. Streamlined platforms such as Paypal were also adopted quickly. In the early years, publishers often ran months-long online preorders for forthcoming products, in an effort to pay for a print run in the thousands of copies, which was close to the minimum for traditional offset printing. By the $2010 \mathrm{~s}$, crowdfunding and high-quality digital printing would later replace preorders entirely and reduce the minimums for quality printed products. In the early 2000 s, several multipublisher fulfillment houses were established, complete with online storefronts, but the unexpected collapse of the fulfillment house Wizard's Attic in the mid2000s left many small publishers with huge financial debts from unpaid revenues and copies of their games that were never returned. Since then, publishers have mainly sold games online through their own websites and Amazon, in addition to working with traditional print distributors that service book and game stores.

In terms of purely digital distribution, the PDF market for TRPG products is huge and fairly unique to the medium, operating independently of the more 
recently established ebook market. Many digital TRPG products were initially distributed for free or as shareware. Early TRPG fan sites often included "netbooks" (before the term "netbook" referred to a small, internet-capable laptop), which were unauthorized fan supplements for commercially published TRPGs. Among the most common free TRPG products were blank character sheets. By the late 1990s, PDF had become the dominant format for transmitted fixed documents and was also commonly used in online TRPG piracy to share scanned copies of otherwise expensive and space-consuming collections of rulebooks.

Monte Cook left Wizards around the launch of third edition, and formed Malhavoc Press with the intention of publishing third-party material for the game. Cook initially experimented by releasing a PDF supplement for D\&D called The Book of Eldritch Might in May of 2001, which almost immediately sold several thousand copies and proved that there was a substantial market for d20 PDFs, especially for a well-known designer. ${ }^{6}$ Later in 2001 - the same year that Apple launched the iTunes Store - the TRPG entrepreneur James Mathe founded a service called RPGNow, an online marketplace where publishers could create accounts and sell PDFs to customers in a central location. In the beginning, the

${ }^{6}$ Monte Cook, "10 Years: From Idea to Industry," The Chapel Perilous: Monte Cook's Journal, May 29, 2011, http://montecook.livejournal.com/242735.html 
bestselling products on RPGNow were nearly always $\mathrm{d} 20$ products. Mathe made attempts to reach out to established publishers of other types of games, but many were hesitant about selling digital versions, worried that it would increase piracy or cannibalize existing print sales. Nevertheless RPGNow recorded better than $10 \%$ growth in every year of its operation. ${ }^{7}$

BitTorrent became a turning point. The peer-to-peer file-sharing software was released in 2001, but by 2004 it was reported to account for $1 / 3$ of all Internet traffic. While most of this traffic did not consist of pirated TRPGs, gaming materials were commonly found on torrents. In the end, Steve Wieck-formerly of White Wolf-founded a rival service to RPGNow, know as DriveThruRPG, offering a variety of anti-piracy DRM measures, promoting significantly higher PDF prices that were closer to the cover price of print copies, and attracting many established non-d20 publishers. Most of the DRM measure were quickly discontinued in reaction to fan complaints, and, in 2006, the two companies merged, creating a PDF distributor with an overwhelming share of the market, which later become the PDF sales service for Wizards' products as well.

\subsubsection{Countercurrents: Indie RPGs}

As these new technologies made it steadily easier and less risky to publish TRPGs, many new games and supplements challenged popular perceptions about

\footnotetext{
${ }^{7}$ Personal correspondence with James Mathe, May 19, 2015.
} 
what TRPGs were, how they should be played, and what subject matter they could explore. Building on the work of earlier vanguard designers such as Greg Costikyan, Robin Laws, John Tynes, Jonathan Tweet, Jenna Moran, and James Wallis - many of whom published some of their games through Wallis' UK-based Hogshead Publishing - a minority of TRPG designers continue to experiment procedurally, in content, and in the form of their products. While "new style" games - to borrow Wallis' branding for them - continued to be a minority in terms of sales and popularity, their influence was substantial and continues to this day.

One major source of new style games has been the loosely connected and self-identified "indie RPGs" movement, parallel to and directly inspired by contemporaneous indie movements in comics, music, film, and digital games. The roots of this movement date back to the Usenet newsgroup rec.games.frp.advocacy (RGFA), which split off from the more general rec.games.frp.misc in May 1992. As John Kim explains, "in the process of hashing out differences, a set of contributors began to actually discuss core concepts of role-playing: what it is, how it works, what styles and techniques exist, how to do it better... [leading to] an acknowledgement that there are different valid styles of role-playing. Different role-playing games are not merely different methods to achieve the same goals, but actually different goals in 
themselves." ${ }^{\prime \prime}$ In 1997, RGFA participants developed the "Threefold Model" typology, categorizing styles of TRPG play as examples of Dramatism, Simulationism, and Gamism.

These discussions strongly influenced the web forum indie-rpgs.com, initially founded as Hephaestus' Forge in 1999 and later relaunched as the Forge in 2001. The Forge was moderated by Ron Edwards, the designer and publisher of Sorcerer - initially released as a shareware text file in 1996, a paid PDF in 1998, and a final print edition in 2001. Edwards initially partnered with Ed Healy to launch the site, but relaunched it with fellow indie designer Clinton R. Nixon handling the technical side of things. In 2007, Clinton stepped back and the hosting responsibilities were taken over by another well-known indie designer, D. Vincent Baker, until the forum officially shut down in 2012. The indie RPGs movement has also been organized around Game Chef, an annual game design competition founded by Mike Holmes in 2002; Games on Demand, a structure for pick-up play at conventions developed by Katherine Miller in 2006; Story Games, a more casual web forum created by Andy Kitkowski in 2006; the Independent Game Developers Network, founded by Mark Diaz Truman in YEAR; and most recently by a thriving network of old and new voices on Google Plus.

8 John Kim, "rec.games.frp.advocacy info," Darkshire, January 23, 2007, http://www.darkshire.net/jhkim/rpg/theory/rgfa/ 
Bill White has done an excellent job of chronicling the history of discussions on the Forge, including a number of controversies. ${ }^{9}$ While the central mission of the Forge was to support all designers of creator-owned games in publishing their games however they wanted, the indie RPGs movement that came out of the Forge was also influenced — to varying degrees—by Edwards' views on the theory, design, practice, and publishing of TRPGs, initially captured in a number of short articles: "Nuked Apple Cart" (1998), which argued that TRPG publishing models needed to change; "War Story" (2000), warning designers against signing away their game's rights to an external publisher; and "System Does Matter" (1999), which first put forward Edwards' own adaptation of the RGFA's Threefold Model.

Beyond the typologies, The Forge promoted creator-ownership and selfpublishing over freelance game design on a work-for-hire basis, the latter of which was and is still often the standard in the industry. It also promoted the idea that every aspect of a game's rules should be carefully designed to emphasize the game's core themes, rather than relying on popular TRPG conventions. This meant that games were often modeled as structuralist emulations of particular genres. The game designer was viewed as an auteur, producing unique and special

\footnotetext{
${ }^{9}$ Cite Bill's article on AP and the Forge, or his forthcoming edited volume.
} 
rules that were designed very intentionally to produce a specific kind of roleplaying experience. Consequently, indie TRPGs often took responsibility for and authority over the game experience away from the GM and gave it to the game designer or the players. Responsibility for less-optimal play experience was thought to lie either with the game designer for poor design and explanation or with the players for not playing the game "properly."

Generally speaking, the Forge tradition was fairly skeptical of GMs, who were thought to often bring their own inappropriate concepts to the game or even sweep aside core parts of the rules. Instead, indie RPGs often included strict rules about framing scenes and conflicts, often combined with very explicit pacing mechanics about when things should happen. This essentially converted many traditional GM responsibilities into mechanics, theoretically allowing the game designer a much higher degree of control over what happens at the table. GMless, cooperative games have also become increasingly common, paralleling the emergence of cooperative board games. In addition, indie RPGs often focused on characters facing zero-sum choices, in which they couldn't get everything they wanted and making certain choices closed off other options forever. The goal here was to make player choices significant in determining what happened in the fiction of the game, countering the perceived dominant play style of having the GM pre-plan all situations and conflicts in advance, including often pre-planning the outcomes. Even when indie games were about an inescapable oncoming 
doom, the way in which that doom played out and what it meant were typically up in the air. In a famous phrase, Vincent Baker dubbed this "playing to find out what happens."

As there's no way to cover all the indie games published, the following bullets briefly describe the annual "Best Game" winners of the peer-voted Indie RPG Awards, founded by Andy Kitkowski in 2002 and more recently organized by John Kim:

- Dust Devils (2002) by Matt Snyder is a minimalist Western game in which gunslingers wrestle with their own weaknesses and vices.

- My Life with Master (2003) by Paul Czege asks players to portray the minions of an evil master, sent to do foul deeds. Do they eventually revolt?

- Dogs in the Vineyard (2004) by D. Vincent Baker is another Western about teenage Mormon lawmen. What justice will they choose to dispense?

- Polaris (2005) by Ben Lehman is a 4-player game with distinct rotating roles, telling the tragic story of a doomed kingdom of arctic elves.

- Spirit of the Century (2006) by Rob Donoghue, Fred Hicks, and Leonard Balsera is a Fudge variant about pulp action heroes in the early 1900s. 
- Grey Ranks (2007) by Jason Morningstar asks each player to portray “a young Polish partisan before, during, and after the disastrous 1944 uprising."

- Mouse Guard (2008) by Luke Crane and David Petersen, based on the popular comic book series, is about warrior mice trying to survive in a harsh world.

- Kagematsu (2009) by Danielle Lewon asks a female player to portray a male Japanese warrior who is being asked to defend a village from threats.

- Apocalypse World (2010) by D. Vincent Baker is a post-apocalyptic game with innovative rules and a tightly structured GM role.

- Do: Pilgrims of the Flying Temple (2011) by Daniel Solis is a storytelling game about flying child monks trying to solve other people's problems.

- Dungeon World (2012) by Sage LaTorra and Adam Koebel is a variation on Apocalypse World that's focused on $D \& D$-style dungeon adventures.

- Hillfolk (2013) by Robin Laws brought things full circle, as Laws' games helped inspire the indie RPGs movement in the first place.

Note that there are other games that focus on romance, colonialism, slavery, dictatorships, the drug trade, mental illness, sex, road trips, disco, crows, architecture, and childhood, including many structurally experimental and emotionally intense TRPGs. 
The relatively specific “indie RPGs" movement (a problematic label, but one with no obvious alternative) is not the entirety of independently produced TRPGs, not by a long shot. A larger number of other independent designers exist among fans of more traditional or conventional styles of play. Most d20 publishers, after all, were one-person creator-owned operations.

As another example, contemporary indie designers have also attempted to revitalize the play communities around early TRPGs, both out of nostalgia and from a preference or desire for styles of play that are less well supported by more recent editions of $D \& D$ and other classic games. This has led to a number of "retro-clones," games that take advantage of the OGL to recreate older editions of D\&D and allow others to release new content for these editions. Among the most well known of these, Matthew Finch's Swords \& Wizardry (2008) is based on the original 1974 version of D\&D, Stewart Marshall's OSRIC (2006) is based on AD\&D, and Daniel Proctor's Labyrinth Lord (2007) is based on the "basic/expert" edition of 1981. There are also other games that don't try to recreate older games but still clearly and openly draw inspiration from 1970s and early 1980s TRPGs, including Jeremy Crawford's Stars Without Number (2010), James Raggi's Lamentations of the Flame Princess (2010), Alexander Macris, Tavis Allison, and Greg Tito’s Adventurer Conqueror King (2012), Goodman Games' Dungeon Crawl Classics RPG (2012), and Christopher McDowall's Into the Odd (2013). 
While this movement is often known as the Old School Renaissance (OSR), the recent popularity of the 20th-anniversary editions of the World of Darkness games and the continuing popularity of $D \& D$ 's 2000 edition (in multiple forms) illustrates that this trend is not limited to just games from the 1970s and 1980s. More generally, the continuing popularity of older games, their revivification in the hands of independent creators, and the cultivation of related fan communities represents resistance to the much-criticized "supplement treadmill" or "periodical model" of TRPG publishing, which asks fans to continually upgrade the procedures and content of their play by buying the newest versions and supplements for their favorite TRPG brands. While the refusal of a portion of a game's fan base to upgrade - sparking an "edition war" of differing preferences between fans of the same game-is a long-establish dynamic in TRPG publishing, the extent of the current rejection is so significant that major publishers such as Wizards, White Wolf (or at least its successor, Onyx Path), and Fantasy Flight are being forced to take notice.

\subsubsection{Digital Mirages: Challenges and Opportunities in Hybridity}

The past decade of TRPG history has played out like a morality tale about the fickle promises of full digitalization, particularly for two of the most established publishers, White Wolf and Wizards.

During the d20 era, White Wolf attempted to take advantage of the renaissance in fantasy games in multiple ways. Most obviously, they created their 
own d20 imprint, Sword \& Sorcery, licensing the print rights to all of the PDF products published by Monte Cook's Malhavoc Press, licensing the classic Ravenloft and Gamma World settings from Wizards', and publishing d20 TRPG adaptations of the popular EverQuest (2002) and World of Warcraft (2003) MMORGs. Less obviously, White Wolf lunched a new, highly successful, nond20 fantasy line with Exalted (2001), an anime- and JRPG-inspired game using a variation on their existing "storyteller" system and taking place in an ancient, mythological setting that supposedly existed before the World of Darkness. The Exalted line would ultimately end up being more successful than most of their other games, earning many supplements and a second edition in 2006.

In the early 2000s, the decision was also made to conclude and relaunch the entire World of Darkness. The most recent edition of Vampire: The Masquerade had been published in 1998, sales figures were not what they once were, and White Wolf was perhaps inspired by Wizards' success with D\&D3. In any event, the original World of Darkness was destroyed with apocalyptic fanfare in 2004, though a series of supplements for the various monster types, and the new World of Darkness launched with a core rulebook—a different move for White Wolf, since they'd always had each game line stand alone - and Vampire: The Requiem (2004). While some aspects were similar, the new game removed nearly all of the clans and trademark vampire powers of the original game, replacing them with an Exalted-inspired set of five clans and five factions that 
vampires could now belong to. Long-time fans were often upset by this change, but White Wolf stuck to their guns and dramatically re-envisioned many of its other classic lines as well. But while sales were strong initially, they quickly fell off. ${ }^{10}$

In 2006, White Wolf was purchased by CCP Games, the Icelandic video game company responsible for EVE Online (2003). CCP hoped to use their experience with $E V E$ to create a World of Darkness MMORG that was unlike anything else on the market. White Wolf's properties had previously been the inspiration for a cult digital game, Troika Games' Vampire: The MasqueradeBloodlines (2004), which was released with many flaws but is still considered a classic due to its innovative structure and storytelling. Initially, it didn't seem like the acquisition of White Wolf would change things very much, but that changed over the next few years as staff were pulled from White Wolf to work on the $\mathrm{MMO}$ and Ryan Dancey—-the person behind the OGL, now working for CCPsaid "The focus of the company is on making MMOs and our legacy table top business is a legacy business." ${ }^{11}$ White Wolf continued to publish a few game products, but they were very minimal. CCP itself faced major issues with EVE Online, which took up increasingly attention and very gradually led to

\footnotetext{
${ }^{10}$ Appelcline, Designers \& Dragons, Vol. 3: The Nineties, 42.

${ }^{11}$ As quoted in Appelcline, Designers \& Dragons, Vol. 3: The Nineties, 45.
} 
cancellation of the World of Darkness MMO, which seemed inevitable to observers and yet didn't finally happen until 2014.

Yet, just when digital mirages seemed to have killed one of TRPGs most successful publishers, digital technologies also helped save White Wolf, though in a new form. In the midst of this crisis, White Wolf made the fortuitous decision to hire a team of veterans to create a 20th anniversary edition of Vampire: The Masquerade that combined, condensed, and revamped the best material across all the game's editions. While "V20," as it was called, was made possible by an old fashioned pre-order and custom print job, the project was so successful that a new company—Onyx Path—was created by several White Wolf vets, licensing the rights to White Wolf properties from CCP and then using the Kickstarter crowdfunding service to raise money for PDF and print-on-demand products, the latter of which had just recently become available through DriveThruRPG/RPGNow (also owned by a former White Wolf staffer). By going PDF and POD only, Onyx Path could invest zero money in print runs-which meant waiting until they sold and the publisher was paid back by distributorsand working with DriveThru meant they didn't even need to handle sales themselves. This has proven to be a hugely successful and relatively risk-free model for them, meaning that White Wolf's games are flourishing again, even though they are rarely in game stores and are published by a different company. 
The tale of Wizards and the last two editions of D\&D is more straightforward. Following the $\mathrm{d} 20$ boom and subsequent oversaturation, Wizards tried a different approach with D\&D4, released in 2008. Clearly inspired by digital gamesparticularly World of Warcraft — despite some repeated denials, the designers turned D\&D into a tactical miniatures-based battle game linked by interludes where characters might attempt various challenges before finding themselves in another often pre-determined battle. While some folks played previous editions of D\&D in this style, D\&D4 designed this approach into the core mechanics of the game, complete with mandatory miniatures and battle maps (more things to buy), fun combat powers for every class that were meant to be printed on cards (more things to buy), and classes with specific combat roles as in MMO raid parties. Essentially, while many of these were optional elements in D\&D3 and 3.5, D\&D4 was built specifically around this method. As an added bonus, the designers felt that this focused approach—rather than something more open to GM and player interpretations - could be more easily translated into online play, backed by a newly announced software platform.

Many indie game designers were excited about this new approach. Finally, a focused version of D\&D that's explicit about what kind of game it is! New players also seemed to like the elements inspired by board, card, and digital games. However, existing D\&D fans were less thrilled, partially because the game pushed a particular play style that wasn't necessarily what everyone wanted or 
expected. Additionally, Wizards released a new open content license for D\&D4 that was much more restrictive than the OGL. It was still possible to release compatible products, but not stand-alone games and Wizards' reserved the right to cancel the license. While some third-party publishers still tested the waters, many were put off by the restrictions and sales never really approached what they were for major D\&D3 or even 3.5 products. As for the promised digital tools, they never arrived, aside from an honestly very useful online character and monster generators, which Wizards' sold monthly access to.

The mediocre success of D\&D4, at least by the standards of third edition, opened the doorway for Paizo Publishing and their game Pathfinder —inspired by their successful third edition adventure line of the same name- to steal D\&D's crown over the next few years. Pathfinder, published in 2009, was a fairly restrained revision of D\&D3.5, fixing things that annoyed fans while leaving the bulk of the rules intact and familiar. Paizo advertised the game as being for fans who didn't want to make the jump to fourth edition but still wanted a new game. Additionally, Paizo conducted open beta testing among fans, releasing a fully playable version of the game as a free PDF file and soliciting feedback. As a result, by the early 2010s, Pathfinder was often ranked as a more popular game than $D \& D$, even if it was essentially $D \& D$.

At first, Wizards responded by releasing a somewhat revised version of D\&D4, similar to what they'd previously done with 3.5 , though this new version 
was simply called $D \& D$ Essentials (2010) and was published in a smaller trade paperback size (rather than $8.5 \times 11$ hardcovers), similar to the dimensions that have become popular for indie RPGs. While the Essentials series received widespread critical acclaim for improving many issues with D\&D4 and making it more accessible, it didn't seem to make much of a dent in the growing success of Pathfinder.

Wizards announced a first edition of D\&D in 2012, under the working title of "D\&D Next." Learning from Paizo and taking advantage of digital technologies, D\&D5 received an extensive open beta test though distribution of free PDF files - though to get them you had to sign up on the D\&D website - and the game was finally released in 2014 . While it's too early to make a fully accurate assessment of the game's success, signs are positive, including recent comments by Mike Mearls. The game appears to be largely a return to the prefourth days, but with revisions and innovations that really liven up and streamline many aspects of the game. There have been some efforts by former D\&D designers to "pull a Paizo" and take advantage of portions of the audience that may be looking for something else — such as 13th Age (2013) by Rob Heinsoo and Jonathan Tweet and Numenera (2013) by Monte Cook- but the success of those games hasn't seemed to have harmed fifth edition at all. Neither has the growing might of Fantasy Flight in the TRPG market through their Warhammer 40,000 and Star Wars games. So far, there is no open content license for the current 
edition of $D \& D$, though Wizards has partnered with specific publishers on specific products, and there are rumors and something broader might be coming. The limited number of publications seems to have been accepted by fans as an opportunity to create their own non-commercial materials and a relief from purchase exhaustion, rather than something lacking.

\subsubsection{Forward to Tomorrow}

Recent evidence suggests that gaming is not a zero-sum game. The success of the digital games industry and peer analog game mediums such as board games, card games, and larp seem to have synergistically promoted an appreciation for and interest in TRPGs among younger generations of gamers. The contemporary attendees of Gen Con or PAX are typically consumers of a wide variety of digital and analog games, of which TRPGs are often a part. There are also hybrid mediums emerging that combine elements from tabletop, live action, card, board, educational, "serious," and/or digital games to create new forms of play.

The demographics of TRPGs are changing. The passing of Gary Gygax in 2008 and Dave Arneson in 2009 was mourned across the TRPG landscape, but it also occurred as the older "grognard" generation that started with early $D \& D$ and the generation that became hooked in the 1980s and 1990s found themselves sharing the table — both literally and figuratively—with younger generations raised on modern CRPGs. This younger "video game generation" is noticeably more diverse - at least in terms of gender and ethnicity — and seems to be more 
open to different kinds of TRPG experiences. As in video games, comics, and other mediums that have been framed as majority white and male, there has been some backlash against this diversification — manifesting prominently in arguments about the visual or written portrayal (or lack thereof) of women and people of color in TRPG publications, as well as many cases of online or in-person harassment or mistreatment. At present, queer participants and those living with disabilities seem to be welcomed more warmly, though there are continuing struggles there as well.

The social status of TRPGs in U.S. society has also changed. While TRPGs are often considered to be a touchstone of nerd or geek culture-perhaps most famously represented in the Dead Alewives comedy sketch "Attacking the Darkness" (1996) — the rising social status of both games (thanks to the profitability and rising social status of digital games) and nerds (thanks to the profitability and rising social status of tech industry jobs) have gradually transformed gaming into something that's cool or at least interesting for adults to be involved in, rather than something inherently shameful and juvenile. The changing demographics have also helped bring TRPGs closer to the mainstream, as have the buzz surrounding "gamification" and other game-based social engineering projects. The publication of this book - a major landmark project in TRPG studies - is a testimony to how much things have changed. 
The relationship between international TRPG communities and markets and those of the United States remains both fruitful and problematic. Games published by American companies and creators often dominate multinational, national, and local TRPG communities abroad, either among populations fluent in English or through localized translations. While there are many countries with strong local traditions of TRPGs — including Canada, the UK, France, Germany, Italy, the Nordic countries, Brazil, and Japan, among others_-it has not been a two-way street, with international games typically finding limited success in the United States. That said, some U.S.-based TRPG publishers do make an effort to hire international creators, particularly as visual artists but also as writers and designers. Additionally, many international games are very successful in their local TRPG communities and are more often recognized there (including by government arts funders) as important creative works, since TRPGs operate in a different and arguably less baggage-filled context in many countries. More international connections are now being built, thanks to the Internet, so there is hope for a more integrated future.

In the digital age, TRPGs are not a dead medium or even the kind of partially revived "zombie" media described by Garnet Hertz and Jussi 
Parikka. ${ }^{12}$ They have been left behind in narratives of progress and digitization in mainstream game studies, but they are very much alive, in fact, more alive than ever before. The current state of TRPGs is more like Frankenstein's monster: put together from media that were assumed to be dead but galvanized—to true life, not undeath—by the electricity of the digital age, a hodge-podge of different overlapping parts that function together as a surprisingly robust, powerful, and yet misunderstood whole.

\section{Further Reading}

Appelcline, Shannon. 2014. Designers \& Dragons (4 vols.). Silver Spring, MD: Evil Hat, Inc. [Kindle edition]

Fine, Gary Alan. 1983. Shared Fantasy. Chicago, IL: University of Chicago Press.

Mackay, Daniel. 2001. The Fantasy Role-Playing Game: A New Performing Art. Jefferson, NC: McFarland \& Co.

Peterson, Jon. 2012. Playing at the World: A History of Simulating Wars, People, and Fantastic Adventures, from Chess to Role-Playing Games. San Diego, CA: Unreason Press.

\section{References}

12 Garnet Hertz and Jussi Parikka, "Zombie Media: Circuit Bending Media Archaeology into an Art Method," Leonardo 45, no. 5 (2012). 
Allston, Aaron, Steven Long, and Darren Watts. 2006. Champions: Superpowered Roleplaying (25 th Anniversary Edition). San Francisco, CA: DOJ, Inc.

Appelcline, Shannon. 2013. Designers and Dragons (4 vol.). Silver Spring, MD: Evil Hat, Inc.

Baker, Vincent. 2004. Dogs in the Vineyard. USA: Lumpley Games.

Bergström, Karl. 2012. "Creativity Rules: How Rules Impact Player Creativity in Three Tabletop Role-Playing Games.” International Journal of RolePlaying, no. 3: 4-17. http://www.ijrp.subcultures.nl/wpcontent/issue3/IJRPissue3.pdf.

Boss, Emily Care. 2012.

Charlton, Coleman, John Curtis, Pete Fenlon, and Steve Marvin. 1980. Rolemaster. Charlottesville, VA: Iron Crown Enterprises.

Costikyan, Greg. 2013.

Czege, Paul. 2003. My Life With Master. USA: Half Meme Press.

Dormans, J. 2006. "On the Role of the Die: A Brief Ludologic Study of Pen-andPaper Roleplaying Games and Their Rules." Game Studies 6 (1). http://gamestudies.org/0601/articles/dormans.

Edwards, Ron. 2004. “System Does Matter.” http://www.indierpgs.com/_articles/system_does_matter.html.

Fine, Gary Alan. 1983. Shared Fantasy: Role-Playing Games as Social Worlds. Chicago, IL: University of Chicago Press. 
Freeman, Jon. 1979. Playboy Winner's Guide to Board Game. Chicago, IL: Playboy Press.

Glancy, A. Scott. 2009. "World without End: The Delta Green Open Campaign Setting." In Third Person: Authoring Vast Narratives, eds. Pat Harrigan and Noah Wardrip-Fruin, 77-85. Cambridge, MA: MIT Press.

Gygax, Gary, and Dave Arneson. 1974. Dungeons \& Dragons. Lake Geneva, WI: TSR.

Hammer, Jessica. 2007. "Agency and Authority in Role-Playing 'Texts." In $A$ New Literacies Sampler, eds. Michele Knobel and Colin Lankshear, 6793. New York: Peter Lang.

Harper, John. 2006. Agon. Self-published on Lulu.

Healy, Ed, and Ron Edwards. 1999. The Forge. www.indie-rpgs.com/

Herber, Keith. 2007. “On ‘The Haunted House.” In Second Person: Role-Playing and Story in Games and Playable Media, eds. Pat Harrigan and Noah Wardrip-Fruin, 41-43. Cambridge, MA: MIT Press.

Hicks, Fred, and Rob Donoghue. Fate. Silver Spring, MD: Evil Hat Productions. Hindmarch, Will. 2007. "Storytelling Games as a Creative Medium.” In Second Person: Role-Playing and Story in Games and Playable Media, eds. Pat Harrigan and Noah Wardrip-Fruin, 47-55. Cambridge, MA: MIT Press.

Hitchens, Michael, and Anders Drachen. 2008. “The Many Faces of Role-Playing Games.” International Journal of Role-Playing, no. 1: 3-21. 
http://www.ijrp.subcultures.nl/wpcontent/uploads/2009/01/hitchens_drachen the many_faces_of_rpgs.pdf.

Hite, Kenneth. 2007. "Narrative Structure and Creative Tension in Call of Cthulhu." In Second Person: Role-Playing and Story in Games and Playable Media, eds. Pat Harrigan and Noah Wardrip-Fruin, 31-43. Cambridge, MA: MIT Press.

Hite, Kenneth. 2010. Nights Black Agents. London, England: Pelgrane Press. Hite, Kenneth. 2014. Personal communication.

Jackson, Steve. 1986. Generic Universal Role-Playing System (GURPS). Austin, TX: Steve Jackson Games.

Jara, David. 2013. "A Closer Look at the (Rule-) Books: Framings and Paratexts in Tabletop Role-Playing Games.” International Journal of Role-Playing 1 (4): 39-54. http://www.ijrp.subcultures.nl/wpcontent/issue4/IJRPissue4jara.pdf.

Lehman, Ben. 2005. Polaris: Chivalric Tragedy at Utmost North. USA: These Are Our Games.

Lortz, Stephen, L., 1979. Role-playing. Different Worlds 1:36-41.

Miller, Marc. 1977. Traveller. Normal, IL: Game Designers' Workshop. Mona, Erik. 2007. "From the Basement to the Basic Set: The Early Years of Dungeons \& Dragons." In Second Person: Role-Playing and Story in 
Games and Playable Media, eds. Pat Harrigan and Noah Wardrip-Fruin, 25-30. Cambridge, MA: MIT Press.

Moran, Jenna, K., 1999. Nobilis. Pharos Press. (Written under the name R. Sean Borgstrom).

Morningstar, Jason. 2009. Fiasco. Chapel Hill, NC: Bully Pulpit Games.

Perrin, Steve. 1978. Runequest. Oakland, CA: Chaosium.

Petersen, Sandy. 1981. Call of Cthulhu. Oakland, CA: Chaosium.

Peterson, Jon. 2012. Playing at the World: A History of Simulating Wars, People, and Fantastic Adventures, from Chess to Role-Playing Games. San Diego, CA: Unreason Press.

Price, Robert M. 2009. “With Strange Aeons: H.P. Lovecraft's Cthulhu Mythos as One Vast Narrative.” In Third Person: Authoring Vast Narratives, eds. Pat Harrigan and Noah Wardrip-Fruin, 225-242. Cambridge, MA: MIT Press.

Rein-Hagen, Mark. 1991. Vampire: The Masquerade. Stone Mountain, GA: White Wolf Publishing.

St. Andre, Ken. Tunnels \& Trolls. Flying Buffalo, Inc. Stafford, Greg. 1985. Pendragon. Oakland, CA: Chaosium.

Torner, Evan. 2014. "Uncertainty in Analog Role-Playing Games, Part 2.” Analog Game Studies 1.2. http://analoggamestudies.org/2014/09/uncertainty-inanalog-role-playing-games-part-2/ 
Tresca, Michael J. 2011. The Evolution of Fantasy Role-Playing Games. Jefferson, NC: McFarland \& Co.

Tweet, Jonathan, and Mark Rein-Hagen. 1987. Ars Magica. Northfield, MN: Lion Rampant Games.

Walkerp. 2008, March 17. “Re: [GURPS] Is the complexity an illusion?” [online discussion]. In [GURPS] Is the complexity an illusion? \#10 RPG.net. Path: http://forum.rpg.net/showthread.php?390100-GURPS-Is-thecomplexity-an-illusion.

White, William J. 2013. "The Right to Dream of the Middle Ages: Simulating the Medieval in Tabletop RPGs." In Digital Gaming Re-Imagines the Middle Ages, ed. Daniel T. Kline, 15-28. New York: Routledge. 